\title{
C-Reactive Protein Levels do Not Correlate with Body Mass Index in Patients Hospitalized with Infectious Diseases: A Retrospective Study
}

elena chertok ( $\square$ elenachertok12@gmail.com )

Emek Medical Center

Guy Dori

Emek Medical Center

Naama Schwartz

Carmel Medical Center

Ori Cheshin

Emek Medical Center

Ronit Nitzan

Emek Medical Center

Avraham Ishay

Emek Medical Center

\section{Research Article}

Keywords: CRP level, acute infection , BMI

Posted Date: November 18th, 2021

DOI: https://doi.org/10.21203/rs.3.rs-1034053/v1

License: (9) (i) This work is licensed under a Creative Commons Attribution 4.0 International License. Read Full License 


\section{Abstract}

\section{Background.}

C-reactive protein (CRP) is an acute phase reactant protein synthesized in the liver. Human body proportions, such as body mass index (BMI), may affect CRP levels during infection. This study was carried out to investigate the relationship between CRP and BMI in obese versus non- obese patients hospitalized with common acute infections.

\section{Methods}

A total of 445 patients admitted with diagnoses of pneumonia, urinary tract infections and cellulitis were included in the statistical analysis. Among them, 287 were diagnosed with pneumonia, 80 with UTIs and 78 with cellulitis. Each group was also divided according to their BMI. ( $<$ or $\left.\geq 30 \mathrm{~kg} / \mathrm{m}^{2}\right)$. We gathered data for serial CRP measurements performed on day $0-1,1-3$, and $4-6$ of hospitalization as well as BMI levels for all patients. Other markers of acute inflammation, including WBC, fibrinogen level, LDH, as well as albumin level and GFR were recorded.

\section{Results}

Overall, we found no difference in CRP levels in patients with or without obesity throughout the duration of their hospitalization. There was a trend of elevated CRP level at the beginning of hospitalization in the group with $\mathrm{BMI} \leq 30(\mathrm{p}=0.06)$. No correlation was found between CRP levels and $\mathrm{BMI}$ at the points of measurements during hospitalization in the three study groups.

\section{Conclusion}

CRP levels do not correlate with BMI and with other biomarkers of inflammation in patients hospitalized with acute infectious diseases.

\section{Highlights}

- Baseline CRP level is greater in obese patients $\left(\mathrm{BM}>35 \mathrm{~kg} / \mathrm{m}^{2}\right)$ versus non-obese individuals.

- We compared the CRP levels in obese versus non-obese patients with acute infection.

- Patients with pneumonia, UTI and cellulitis were followed throughout their hospitalization.

- The CRP levels in obese patients were no different from those in non-obese patients throughout hospitalization.

- There is no need to normalize CRP levels by BMI.

\section{Introduction}


CRP is an acute phase protein, synthesized by hepatocytes, in response to IL-6 and IL-1 $\beta$ signalling (1). CRP consists of five identical subunits, each having a binding site for phosphocholine (PC). The binding site serves as a receptor for the PC ligand, found on the cell wall of different microorganisms (2). CRP levels rise rapidly in the presence of high-grade inflammation. During acute infection, CRP levels can rise up to 1000-fold compared to baseline levels (3). Peak CRP levels are typically expected within 24-48 hours after onset of infection $(1,4$,$) . The principal functions of CRP are to protect the host against$ pathogens, remove damaged cells and activate the complement system and other inflammatory pathways $(1,2)$. CRP elevation has been noted in many inflammatory and infectious diseases (3). Almost $90 \%$ of extreme elevations of CRP levels were found to be related to infectious diseases, most frequently, pneumonia and intra-abdominal infections, including cholecystitis, peritonitis and intra-abdominal abscesses (5). The highest elevations of CRP levels were found during the first week of admission to the hospital (5). However, baseline CRP levels can be influenced by different factors, such as age, gender, and weight (3). In patients with severe obesity (BMI $\left.{ }^{3} 35\right)$, baseline CRP levels were significantly elevated compared with their normal weight counterparts (6) and have seen to decrease by $66 \%$ after bariatric surgery (7).

The aim of our study was to assess the relationship between CRP levels and obesity $\left(\mathrm{BMI} 30 \mathrm{~kg} / \mathrm{m}^{2}\right)$ during acute hospitalization for infectious diseases. Specifically, we retrospectively documented CRP levels in obese versus non-obese $\left(B M l<30 \mathrm{~kg} / \mathrm{m}^{2}\right)$ patients who were hospitalized for three common infectious diseases. We hypothesized that in obese patients the peak level of CRP elevation would be greater than that observed in non-obese patients.

\section{Methods}

This retrospective study was conducted in a single medical center, approved by be Institutional Review Board of Emek Medical Center (Helsinki Committee) which waived off the need for informed consent and performed in accordance with the relevant methodological guidelines. The electronic medical records of patients admitted to internal medicine wards between 2016-2019 years with diagnoses of pneumonia, urinary tract infections or cellulitis, with the corresponding ICD-9 codes, were reviewed. Patients were included in the study under three conditions: they were hospitalized for a minimum of three and maximum of seven days, they were 18 years of age or older, and they underwent a minimum of three CRP level measurements during hospitalization. Exclusion criteria were pregnancy, end-stage renal failure treated with dialysis, or death during hospitalization. Patients whose white blood cell (WBC) count was less than 4.500 or CRP level at first measurement was $<0.5 \mathrm{mg} / \mathrm{dl}$ were also excluded to circumvent weak inflammatory responses. Patients with a low Norton score $(<13)$ Patients with a low Norton score $(<13)$ are associated with a low level of mobility, making it difficult to ascertain their weight, and thus these patients were also excluded. A total of 455 patients met the inclusion criteria. Patient gender, age, $\mathrm{BMI}$ and estimated glomerular filtration rate (eGFR) were recorded. Additional data collected included maximal WBC count, maximal fibrinogen and LDH levels together with minimal albumin levels during hospitalization. 


\section{Informed consent statement.}

Informed consent was waived due to the retrospective nature of this study.

\section{Statistical Analysis}

The BMI groups (i.e., BMI $\leq 30$ and BMI $(30>$ ) were compared with a Chi-Square Test (or Fisher's Exact Test) for categorical variables and a T-test (or Wilcoxon rank-sum test) for continuous variables.

Local regression (LOESS) smoothing with 95\% confidence intervals was used to examine CRP trends throughout the hospitalization, stratified for the BMI groups.

As the CRP levels changed during the hospitalization, the CRP measurements were divided into 3 groups according to the time they were measured during the hospitalization: 0 - Categorical variables were presented with frequency and percent and continuous variables were presented with mean \pm standard deviation [median.]

The difference between the infectious groups(pneumonia, UTI and cellulitis) was examined using a ChiSquare Test (or a Fisher's Exact Test), for categorical variables and with ANOVA (or a Kruskal-Wallis test) for continuous variables. Pairwise comparisons were made using Chi-Square Test (or Fisher's Exact Test) for categorical variables and a T-test (or Wilcoxon rank-sum test) for continuous variables. The pairwise comparisons were performed with Bonferroni correction for multiple comparisons.

1 days of admission, 2-4 days of admission and 5-7 days of admission. For each time period during the hospitalization, the difference between the BMI groups in their CRP levels were presented via boxplot and examined with a t-test (or Wilcoxon rank-sum test). For each period of days during hospitalization (0-1 days, 2-4 days and 5-7 days), a scatter plot between the CRP value and the BMI was performed with linear regression.

Statistical analyses and data management were performed using SAS 9.4 software.

P-value $0.05>$ was considered statistically significant.

\section{Results}

Table 1 presents the clinical variables and laboratory values of the three groups of patients, including maximal levels of WBC, LDH, fibrinogen and minimal levels of eGFR, and albumin during hospitalization.

\section{Table 1}

Clinical characteristics and laboratory values of the three study groups. . 


\begin{tabular}{|c|c|c|c|c|}
\hline & Pneumonia & UTI & Cellulitis & \multirow[t]{2}{*}{ P-value } \\
\hline & $\mathrm{N}=287$ & $\mathrm{~N}=80$ & $N=78$ & \\
\hline \multirow[t]{2}{*}{ Age } & 64.5 (17.5) & $69.1(14)$ & $55(15.5)$ & \multirow[t]{2}{*}{$<.0001$} \\
\hline & {$[66,20-94]$} & {$[71,22-93]$} & {$[55,21-85]$} & \\
\hline Gender - male & 172 (59.93\%) & $26(32.5 \%)$ & 53 (67.95\%) & $<.0001$ \\
\hline \multirow[t]{2}{*}{ BMI } & $27.5(6.3)$ & $28.3(5.1)$ & $32.4(8.5)$ & \multirow[t]{2}{*}{$<.0001$} \\
\hline & {$[26.4,14.8-76.5]$} & {$[27.5,18-44.9]$} & {$[30.8,18.7-62.5]$} & \\
\hline \multirow[t]{2}{*}{ GFR } & 69.7 (29.7) & $63.2(25.3)$ & $83.2(28)$ & \multirow[t]{2}{*}{$<.0001$} \\
\hline & {$[75,10-148]$} & {$[60.5,11-122]$} & {$[89,10-140]$} & \\
\hline \multirow[t]{2}{*}{ Norton_score } & 17.1 (2.2) & $16.1(2.4)$ & $17.3(2.1)$ & \multirow[t]{2}{*}{0.0015} \\
\hline & {$[17,13-20]$} & {$[16,13-20]$} & {$[17,13-20]$} & \\
\hline \multirow[t]{2}{*}{ WBCmax } & $14.5(6.1)$ & $13.1(5.8)$ & $13.5(5.2)$ & \multirow[t]{2}{*}{0.1307} \\
\hline & {$[13.7,4-40]$} & {$[11.9,4.8-32]$} & {$[12.6,4.3-31]$} & \\
\hline \multirow[t]{2}{*}{ LDHmax } & $487.3(173.1)$ & 456.5 (233.9) & $448.3(125.8)$ & \multirow[t]{2}{*}{0.0093} \\
\hline & {$[446.5,76-1641]$} & {$[382,240-1800]$} & {$[476,237-726]$} & \\
\hline \multirow[t]{2}{*}{ Albumin_min } & $3.1(0.4)$ & $3.1(0.4)$ & $3.4(0.4)$ & \multirow[t]{2}{*}{0.0013} \\
\hline & {$[3.2,1.5-4.1]$} & {$[3.1,2-4.3]$} & {$[3.4,2.4-4.3]$} & \\
\hline \multirow[t]{2}{*}{ Fibrinogen_max* } & $723.1(190.6)$ & $671.6(184.1)$ & $692.3(177.1)$ & \multirow[t]{2}{*}{0.1472} \\
\hline & {$[704,352-1354]$} & {$[655,392-1257]$} & {$[701,264-1108]$} & \\
\hline Death in 90 days & 13 (4.53\%) & $5(6.25 \%)$ & $0(0 \%)$ & 0.0753 \\
\hline \multicolumn{5}{|c|}{ Continuous variables are presented with mean (SD) [median, range]. } \\
\hline *\%missing: Fibrinc & gen_max 29\%; LDH & nax 13\%; Albumin & $\min 2 \%$ & \\
\hline
\end{tabular}

Patients with cellulitis were younger, their BMI was greater, and their albumin levels decreased, but to a lesser extent than those observed in patients with UTIs or pneumonia. Among patients with UTIs, females were more prevalent. $(p<0.0001)$.

Mortality rates three months after hospitalization were $4.5 \%, 6.3 \%$ and $0 \%$ for patients with pneumonia, UTIs, and cellulitis, respectively ( $p=N S$ ).

Table 2 shows the clinical characteristics and laboratory values of the three groups of infections stratified by their BMI. 
Table 2

Clinical characteristics and laboratory values of the three study groups according to BMIs

\section{A - Pneumonia}

\begin{tabular}{|c|c|c|c|}
\hline & $\mathrm{BMl}<30$ & $\mathrm{BMI} \geq 30$ & P-value \\
\hline & $N=223$ & $N=64$ & \\
\hline Age & $65.2(18)$ & $62.1(15.6)$ & 0.1553 \\
\hline & {$[67,20-94]$} & {$[65,24-88]$} & \\
\hline Gender-male & $143(64.13 \%)$ & $29(45.31 \%)$ & 0.0068 \\
\hline CR & $1.3(1)$ & $1.2(0.6)$ & 0.7924 \\
\hline & {$[1,0.4-7]$} & {$[1,0.4-5.1]$} & \\
\hline GFR & $70.1(30.3)$ & $68.3(27.6)$ & 0.6643 \\
\hline & {$[76,10-148]$} & {$[68.5,10-130]$} & \\
\hline Norton score & 185 (82.96\%) & 53 (82.81\%) & 0.9780 \\
\hline WBCmax & $14.5(6)$ & $14.5(6.4)$ & 0.9535 \\
\hline & {$[13.7,4-39]$} & {$[13.6,5.5-40]$} & \\
\hline LDHmax & $485.8(174)$ & $492.4(171.5)$ & 0.8106 \\
\hline & {$[446,76-1641]$} & {$[453,280-1196]$} & \\
\hline Albumin_min & $3.1(0.4)$ & $3.2(0.4)$ & 0.0196 \\
\hline & {$[3.1,1.8-4.1]$} & {$[3.4,1.5-3.9]$} & \\
\hline Fibrinogen_max* & $728.2(193.4)$ & $705.1(181.2)$ & 0.4732 \\
\hline & {$[715,352-1354]$} & {$[658,441-1199]$} & \\
\hline Death in 90 days & $8(3.59 \%)$ & $5(7.81 \%)$ & 0.1730 \\
\hline
\end{tabular}

Continuous variables are presented with mean (SD) [median, range].

B - UTI 


\begin{tabular}{|c|c|c|c|}
\hline & $\mathrm{BMI}<30$ & $\mathrm{BMI} \geq 30$ & \multirow[t]{2}{*}{ P-value } \\
\hline & $N=58$ & $\mathrm{~N}=22$ & \\
\hline \multirow[t]{2}{*}{ Age } & $69.3(14.6)$ & $68.4(12.3)$ & 0.4250 \\
\hline & {$[71,22-93]$} & {$[66,42-91]$} & \\
\hline Gender - male & $18(31.03 \%)$ & $8(36.36 \%)$ & 0.6495 \\
\hline \multirow[t]{2}{*}{$\mathrm{CR}$} & $1.1(0.5)$ & $1.4(0.9)$ & 0.2380 \\
\hline & {$[1,0.3-3.8]$} & {$[1,0.7-4]$} & \\
\hline \multirow[t]{2}{*}{ GFR } & $65.7(25.3)$ & $56.5(24.6)$ & 0.2336 \\
\hline & {$[62,11-122]$} & {$[59.5,14-98]$} & \\
\hline Norton score & $41(70.69 \%)$ & $11(50 \%)$ & 0.0832 \\
\hline \multirow[t]{2}{*}{ WBCmax } & $13.3(5.4)$ & $12.8(6.9)$ & 0.4377 \\
\hline & {$[11.9,4.8-30]$} & {$[11.4,5.3-32]$} & \\
\hline \multirow[t]{2}{*}{ LDHmax } & $451.9(217.1)$ & $469.5(282.6)$ & 0.7821 \\
\hline & {$[390,256-1800]$} & {$[367,240-1500]$} & \\
\hline \multirow[t]{2}{*}{ Albumin_min } & $3.2(0.4)$ & $3.1(0.4)$ & 0.5602 \\
\hline & {$[3.1,2-4.3]$} & {$[3.1,2.2-3.9]$} & \\
\hline \multirow[t]{2}{*}{ Fibrinogen_max* } & $660.9(170.8)$ & $699.1(218.3)$ & 0.5759 \\
\hline & {$[655,392-1200]$} & [693.5, 424-1257] & \\
\hline Death in 90 days & $3(5.17 \%)$ & $2(9.09 \%)$ & 0.6117 \\
\hline
\end{tabular}




\begin{tabular}{|c|c|c|c|}
\hline & $\mathrm{BMI}<30$ & $\mathrm{BMI} \geq 30$ & \multirow[t]{2}{*}{ P-value } \\
\hline & $N=34$ & $\mathrm{~N}=44$ & \\
\hline \multirow[t]{2}{*}{ Age } & $51.1(17.1)$ & $58(13.7)$ & 0.0643 \\
\hline & {$[53,21-83]$} & {$[56,25-85]$} & \\
\hline Gender-male & 27 (79.41\%) & $26(59.09 \%)$ & 0.0565 \\
\hline \multirow[t]{2}{*}{$\mathrm{CR}$} & $1(0.4)$ & $1.1(1)$ & 0.8040 \\
\hline & {$[0.9,0.6-2.4]$} & {$[0.9,0.5-7.4]$} & \\
\hline \multirow[t]{2}{*}{ GFR } & $86.9(28.8)$ & $80.3(27.5)$ & 0.3101 \\
\hline & {$[90,26-130]$} & {$[87,10-140]$} & \\
\hline Norton score & 31 (91.18\%) & 35 (79.55\%) & 0.1580 \\
\hline \multirow[t]{2}{*}{ WBCmax } & $13.3(6.2)$ & $13.7(4.4)$ & 0.3888 \\
\hline & {$[11.8,4.3-31]$} & {$[12.9,6.4-24]$} & \\
\hline \multirow[t]{2}{*}{ LDHmax } & $422.6(123.4)$ & $462.8(126.8)$ & 0.2588 \\
\hline & {$[398,237-648]$} & {$[484.5,237-726]$} & \\
\hline \multirow[t]{2}{*}{ Albumin_min } & $3.4(0.5)$ & $3.3(0.4)$ & 0.3562 \\
\hline & {$[3.5,2.4-4.3]$} & {$[3.4,2.6-4.2]$} & \\
\hline \multirow[t]{2}{*}{ Fibrinogen_max } & $687.6(189.6)$ & $694.6(173.5)$ & 0.9068 \\
\hline & {$[690,264-1101]$} & {$[705,440-1108]$} & \\
\hline Death in 90 days & $0(0 \%)$ & $0(0 \%)$ & - \\
\hline
\end{tabular}

Overall, in the three groups, most patients with $\mathrm{BM}^{3} 30 \mathrm{~kg} / \mathrm{m}^{2}$ were females, and albumin levels were lowest in the non-obese group.

In the cellulitis group, obese patients were older than patients whose BMI was $<30$. On days 0-1 of hospitalization, the mean CRP level was $12.6 \pm 9.9 \mathrm{mg} / \mathrm{dl}$ for all patients with a $\mathrm{BMl}<30 \mathrm{~kg} / \mathrm{m}^{2}$, and $10.4 \pm 10 \mathrm{mg} / \mathrm{dl}$ for all obese patients $\left(B M \mathrm{~B} \geq 30 \mathrm{~kg} / \mathrm{m}^{2}\right)(p=0.06)$.

On days 2-4 of hospital stay, the mean CRP level was $7.5 \pm 9.5 \mathrm{mg} / \mathrm{dl}$ in the non-obese group vs. $6.5 \pm 6.8$ $\mathrm{mg} / \mathrm{dl}$ in the obese group ( $\mathrm{p}=0.7)$, and $3.7 \pm 4.2$ vs. $4.4 \pm 4.9(\mathrm{p}=0.6)$ on days $5-7$, respectively (Figure 1$)$.As expected, CRP levels were observed to decrease from days 0-1 of hospitalization towards day 7 as shown in figure 2, but a counterintuitive observation was that mean CRP levels in the non-obese group was consistently greater than in the obese group. 
No correlation between BMls and CRP levels was detected at any sampling on days 0-1, 2-4, and 57. (Figure 3).

Other markers of inflammation including LDH, fibrinogen, maximal WBC levels during hospitalization and minimal albumin levels were measured. None of these markers correlated with the maximal CRP levels.

\section{Discussion}

We conducted this study to investigate the correlation between CRP levels and patient BMIs in the setting of three common acute infectious diseases treated in the hospital.

We hypothesized that CRP levels would be greater in patients with greater body dimensions. In contrast to our assumption, our results show insignificant correlation between CRP levels and BMIs in all three infections.

Previous studies found that the level of obesity was a major determinant of the level of CRP increase $(6,7)$.

Increased CRP levels were connected to low grade inflammation, metabolic syndrome, insulin resistance and development of diabetes mellitus $(8,9,10)$. Elevated CRP levels $>3 \mathrm{mg} / \mathrm{dl}$ are associated with the presence of traditional cardiovascular risk factors and increased the probability of cardiovascular events in women with or without metabolic syndrome $(8,9)$.

Previous studies showed that the extent of CRP elevation is related to the severity of the inflammatory response in acute bacterial and viral infections $(11,12,13)$. In hospitalized patients with H1N1 influenza, those with severe disease outcomes had 1.6-fold higher average CRP levels than those with non-severe infection (12). CRP levels were significantly higher in patients with bacterial pneumonia compared to those with H1N1 pneumonia; however, no significant differences in clinical outcomes or mortality were found (13). The main causes for extremely elevated CRP levels ( $>50 \mathrm{mg} / \mathrm{dl}$ ) are infections, most of them bacterial (5).

Recently, CRP levels were assessed in COVID-19 patients on admission. CRP concentrations above the median value $(10.8 \mathrm{mg} / \mathrm{dl})$ were associated with critical illness, mortality rates and thromboembolic events (14). The highest CRP levels were reported in patients with fatal diseases. It is worth noting that the association between CRP levels ( $<$ or $>10,8 \mathrm{mg} / \mathrm{dl}$ ) and all causes of mortality, critical illness, venous thrombo-embolism, and acute kidney injury was not influenced by patients' BMI ( $<30$ and $\geq 30 \mathrm{~kg} / \mathrm{m}^{2}$ ) (14). These results are in concordance with the results of our study where correlation between CRP levels and BMls in each of the three infectious disease groups was poor. We suggest that greater levels of CRP in obese versus non-obese patients may indicate merely a physiologic response, and may not indicate a greater inflammatory response. 


\section{Limitations}

There are some limitations in our study. First, although the three infections were homogenous with respect to the clinical course, we recognized that further stratifying the groups according to the severity of the disease might have impacted the results. Second, in order to focus on the "average" infection and its response, we excluded any extreme forms of disease from the analysis. Third, CRP levels were retrospectively collected from the onset of disease to discharge from the hospital, and we have no data regarding CRP levels following resolution of the acute disease.

In conclusion, in this retrospective study we did not find any significant correlation between CRP levels and BMIs in the setting of inpatients with acute infectious diseases. The surprising finding that CRP levels in the non-obese group were always greater than that in the obese group must draw the clinician's attention to the fact that obesity is not an inherent cause of an increase in CRP levels, at least in the setting of common acute infections, and this warrants further investigation.

\section{Declarations}

\section{Declaration of Competing Interest}

None.

\section{Compliance with Ethical Standards}

Ethical approval for this study was obtained from Ha Emek hospital board review. Approval number : 0115-18-EMC

\section{Funding}

None.

\section{References}

1. Volanakis JE. Human C-reactive protein: expression structure and function. Mol Immunol 2001 .38;23:189-197.

2. Singh SK, Ngwa DN, Agrawal A. Complement activation by C-Reactive Protein Is Critical for Protection of Mice Against Pneumococcal Infection. Front Immunol 2020 .13;11:1812.

3. Sproston R, Ashworth JJ. Role of C-reactive protein at sites of inflammation and infection. Frontiers in Immunology2018.139:754.

4. Rhodes B, Fuernrohr BG, Vyse TJ. C-reactive protein in rheumatology: biology and genetics.Nat Rev Rheumatol 2011;5:282-289. 
5. Vanderschueren S, Deeren D, Knockaert DC, Bobbaers H, Bossuyt X, Peetermans W . Extremely elevated C-reactive protein. Eur J Intern Med. 2006;17:430-433.

6. Cazzo E, Pareja JC, Chaim EA,Coy CSR, Magro DO. Comparison of the levels of C-reactive protein, Glp- 1 and Glp-2 among individuals with diabetes, morbid obesity and healthy controls: an exploratory study. Arq gastroenterol. 2018;55(1):72-77

7. Raghavendra RS. Inflammatory markers and bariatric surgery: a meta-analysis. Inflamm. Res. 2012; 61:789-807.

8. Ridker PM, Buring JE, Cook NR, Rifai N.C-Reactive Protein, the Metabolic Syndrome, and Risk of Incident Cardiovascular Event. An 8-Year Follow-Up of 14719 Initially Healthy American Women. Circulation. 2003;107: 391-397.

9. Ebrahimi M, Heidari-Bakavoli AR, Shoeibi S, Mirhafez SR. Association of Serum hs-CRP Levels with the presence of obesity, diabetes mellitus, and other cardiovascular risk factors. Journal Clinl Lab Anal.2016; 30: 672-676.

10. Laaksonen DE, Niskanen L, Nyyssonen K, et al. C-reactive protein and the development of the metabolic syndrome and diabetes in middle-aged men. Diabetologia 2004;47:1403-1410.

11. Flanders SA, Stein J, Shochat G, Sellers K, Holland M, Maselli J, Drew WL, Reingold AL, Gonzales R. Performance of a bedside C-reactive protein test in the diagnosis of community-acquired pneumonia in adults with acute cough. Am J Med. 2004;116(8):529.

12. Vasileva D, Badawi A. C-reactive protein as a biomarker of severe H1N1 influenza. Inflamm Res 2019;68:39-46.

13. Sohn $\mathrm{CH}$, Ryoo SM, Yoon JY, et al. Comparison of clinical features and outcomes of hospitalized adult patients with novel influenza A (H1N1) pneumonia and other pneumonia. Acad Emerg Med. 2013;20:46-53.

14. Smilowitz NR,Kunichoff D,Garshick M, Shah B, Pillinger M, Hochman JS. C-reactive protein and clinical outcomes in patients with COVID-19. European Heart Journal 2021; 00:1-10.

\section{Figures}




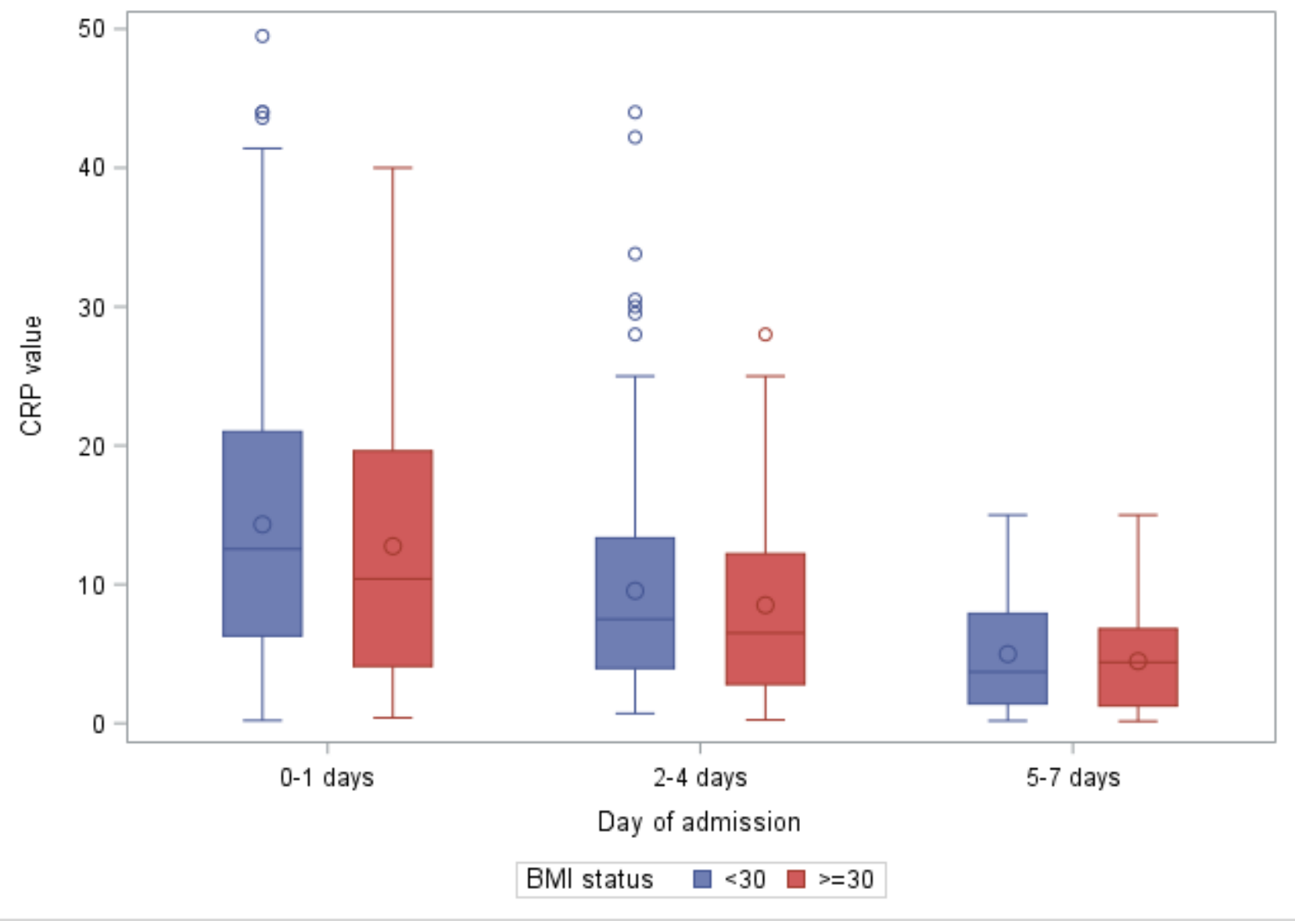

Figure 1

CRP values for all patients stratified by BMI according to days $0-1,2-4$ and 5-7 of hospitalization. 


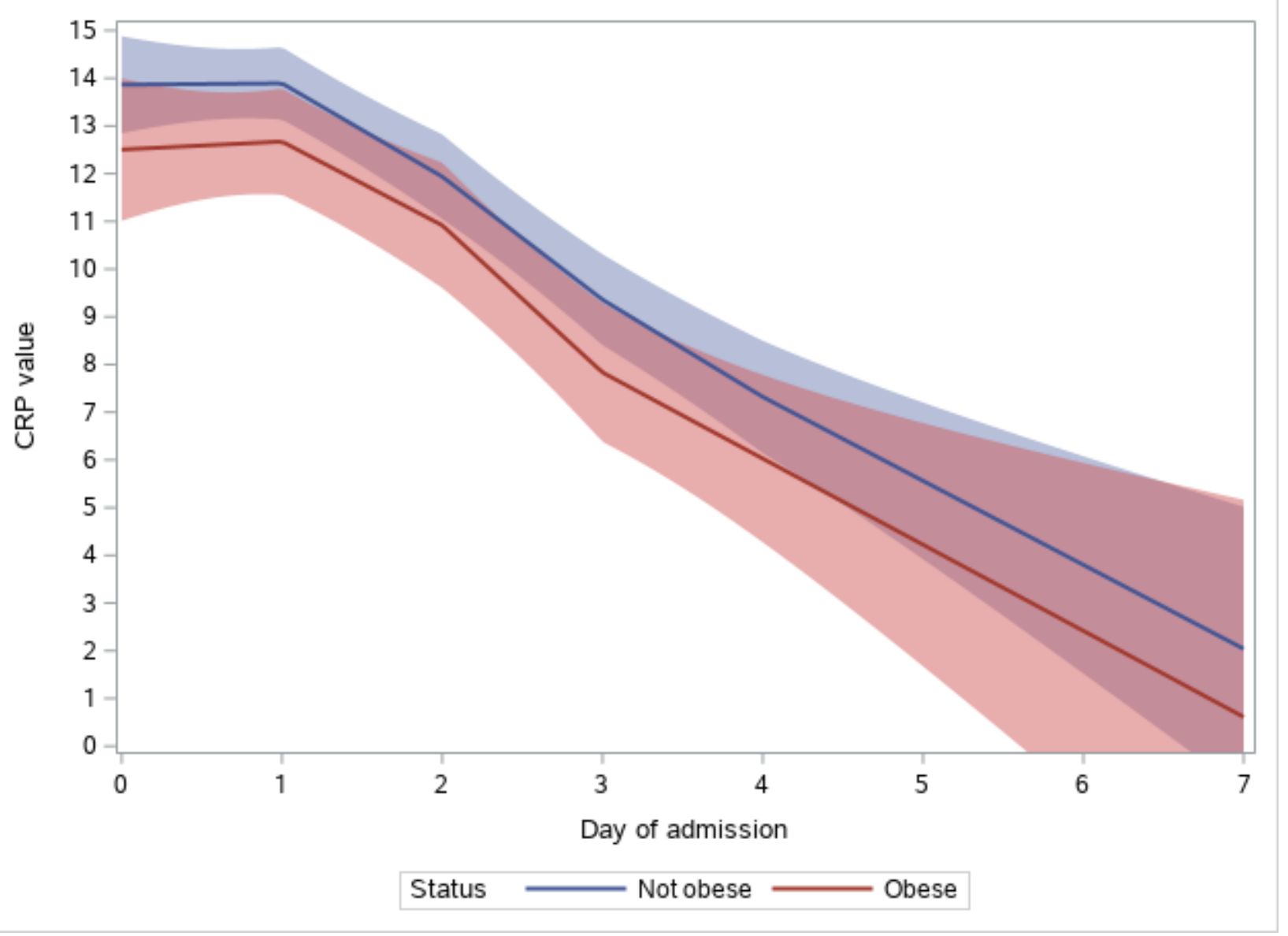

Figure 2

Trajectory of CRP levels over time among obese and non-obese patients. Blue (pink) filling accompanying the blue (red) line indicates confidence interval. Where confidence intervals overlap (purple) the difference between the groups is not significant. 


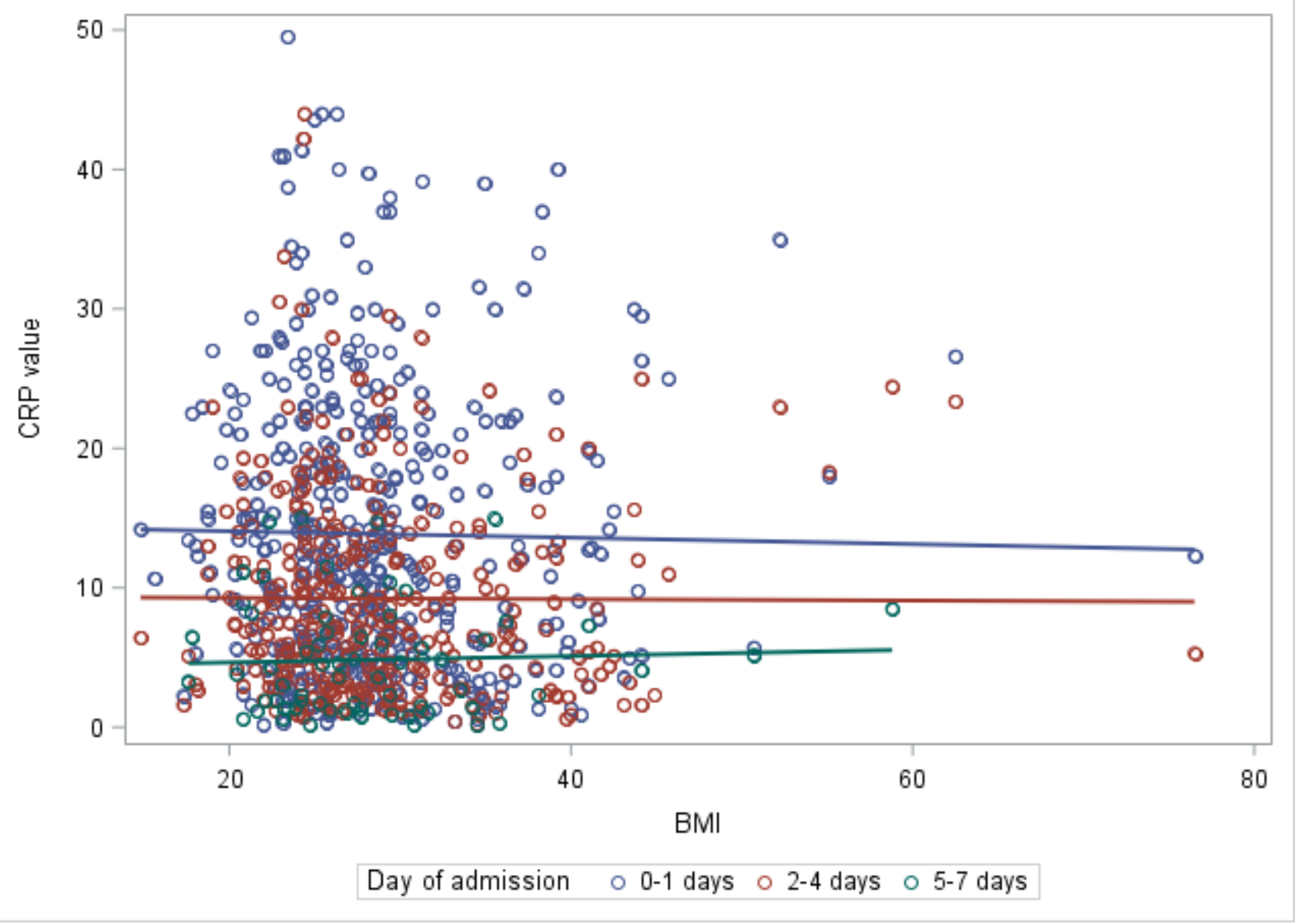

Figure 3

CRP as a function of BMI for all patient groups during hospitalisation 